\title{
Conversion of Temperature Scales
}

\author{
by Manfred Bucher and Hugh A. Williamson \\ Department of Physics, California State University, Fresno, CA 93740
}

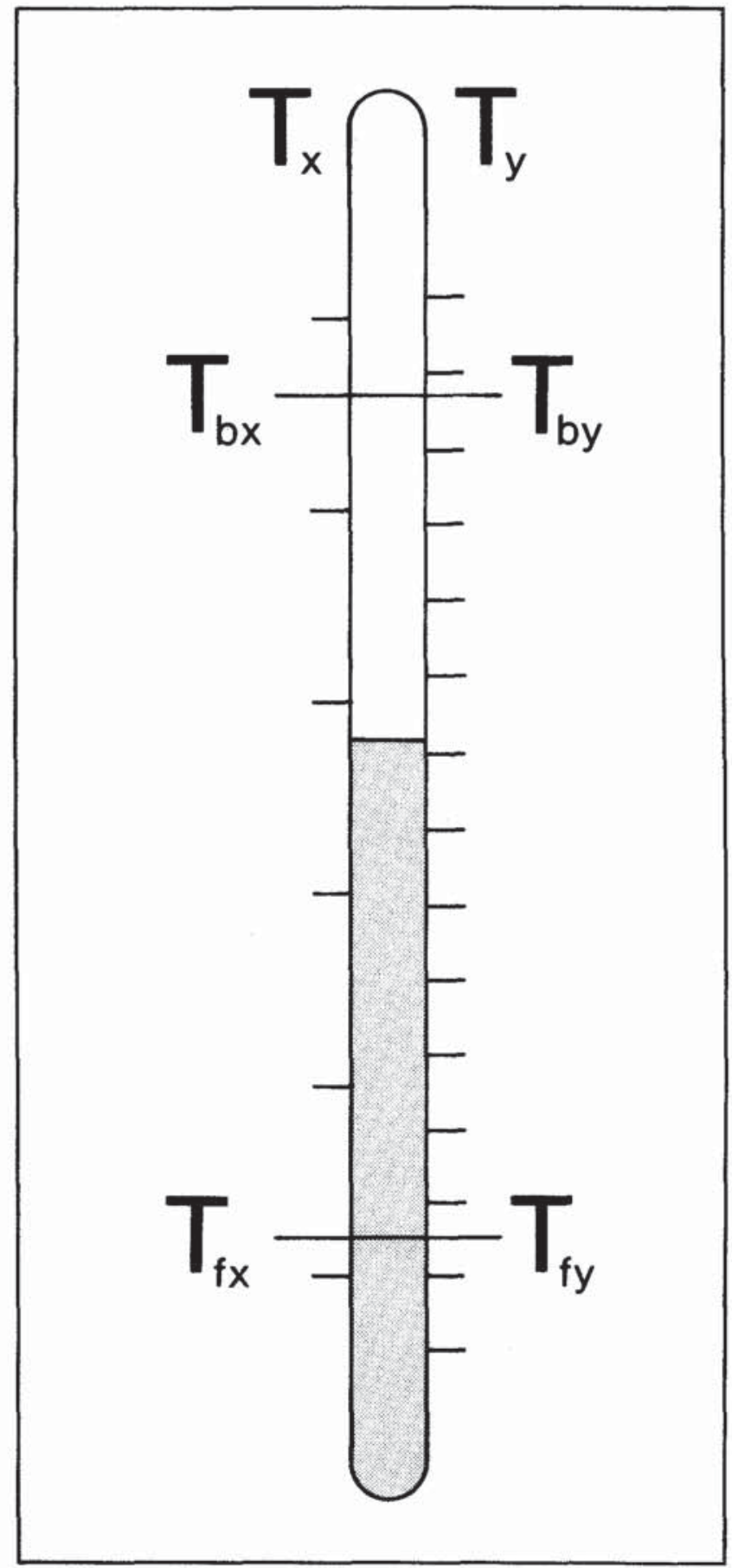

Fig. 1. Traditional side-by-side comparison of two temperature scales, $T_{x}$ and $T_{y}$. The freezing point of water on these scales is denoted by $T_{f x}$ and $T_{f y}$, and the boiling point by $T_{b x}$ and $T_{b y}$, respectively.
Different temperature scales $\mathrm{T}_{\mathrm{x}}$ and $\mathrm{T}_{\mathrm{y}}$, such as Fahrenheit $\left({ }^{\circ} \mathrm{F}\right)$, Celsius $\left({ }^{\circ} \mathrm{C}\right)$, Kelvin $(\mathrm{K})$, or any other scales that might be used for instructional purposes, are usually introduced in textbooks with a graphical side-by-side comparison showing both the freezing point of water at $\mathrm{T}_{\mathrm{fx}}$ and $\mathrm{T}_{\mathrm{fy}}$ and the boiling point at $\mathrm{T}_{\mathrm{bx}}$ and $\mathrm{T}_{\mathrm{by}}$ (see Fig. 1).

This one-dimensional diagram demonstrates nicely the equivalence of different scales. However, this representation is not very convenient for deriving the conversion formulas. In fact, many textbooks present conversion formulas without any derivation. In this note, we propose a simple two-dimensional representation which allows a rapid derivation of temperature scale conversions. It also helps to solve the popular problem of finding the common temperature $T_{s}$ on two different scales.

Our method uses a coordinate system with a $T_{x}$ abscissa and a $T_{y}$ ordinate. We mark the freezing point and boiling point of water by two geometric points with coordinates $\left(\mathrm{T}_{\mathrm{fx}}, \mathrm{T}_{\mathrm{fy}}\right)$ and $\left(\mathrm{T}_{\mathrm{bx}}, \mathrm{T}_{\mathrm{by}}\right)$, respectively (see Fig. 2). The straight line through these points is given by the equation

$$
\mathrm{T}_{\mathrm{y}}=\mathrm{m} \mathrm{T}_{\mathrm{x}}+\mathrm{b}
$$

with slope

$$
\mathrm{m}=\left(\mathrm{T}_{\mathrm{by}}-\mathrm{T}_{\mathrm{fy}}\right) /\left(\mathrm{T}_{\mathrm{bx}}-\mathrm{T}_{\mathrm{fx}}\right)
$$

and ordinate intercept

$$
\mathrm{b}=\mathrm{T}_{\mathrm{by}}-\mathrm{m} \mathrm{T}_{\mathrm{bx}} .
$$

Equation (1) is the conversion formula from a known temperature $\mathrm{T}_{\mathrm{x}}$ to an unknown temperature $\mathrm{T}_{\mathrm{y}}$. The conversion terms $\mathrm{m}$ and $\mathrm{b}$ are readily determined with the known freezing and boiling points on both scales. Examples are $m=(212-32) /(100-0)=9 / 5$ and $\mathrm{b}=212-(9 / 5) 100=32$ for conversion from ${ }^{\circ} \mathrm{C}$ to ${ }^{\circ} \mathrm{F}$ and $\mathrm{m}=$ $100 /(212-32)=5 / 9$ and $b=100-(5 / 9) 212=-17 . \overline{7}$ for the reverse conversion from ${ }^{\circ} \mathrm{F}$ to ${ }^{\circ} \mathrm{C}$.

The common temperature $\mathrm{T}_{\mathrm{s}}$ on both scales is given by the intersection of the (solid) straight line, Eq. (1), with the (dashed) diagonal in Fig. 2 representing

$$
\mathrm{T}_{\mathrm{sy}}=\mathrm{T}_{\mathrm{sx}}=\mathrm{T}_{\mathrm{s}}
$$

Combining Eqs. (1) and (4) gives

$$
\mathrm{T}_{\mathrm{s}}=\mathrm{b} /(1-\mathrm{m}) \text {. }
$$

An example is the common temperature $T_{s}=32 /(1-9 / 5)=$ $-17 . \overline{7} /(1-5 / 9)=-40$ on both the Fahrenheit and Celsius scale. $\square$ 


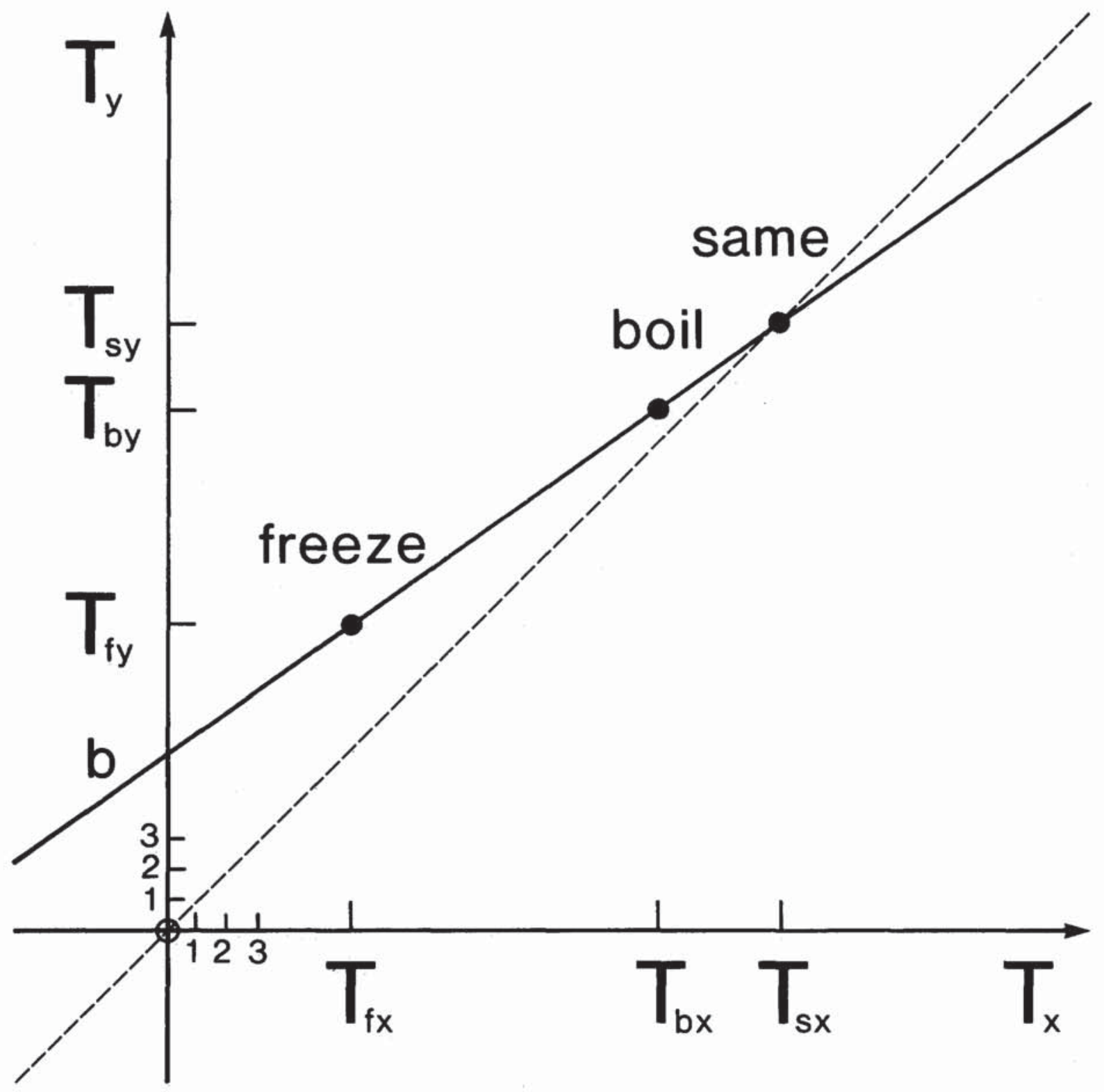

Fig. 2. Temperature conversion diagram with known temperature scale $T_{x}$ as abscissa and scale of unknown temperature $T_{y}$ as ordinate. The linear function $T_{y}\left(T_{x}\right)$ (solid line) is determined with known freezing and boiling points of water on both scales. The intersection of the solid line with the (dashed) diagonal represents the common temperature, $T_{s}$, on both the $T_{x}$ and $T_{y}$ scale. 